\title{
CORRIGENDUM
}

\section{Lifestyle, glucose regulation and the cognitive effects of glucose load in middle-aged adults - CORRIGENDUM}

The publishers regret that the author list in this paper was incomplete. The list of contributing authors should have read:

Leigh M. Riby ${ }^{1 *}$, Jennifer McLaughlin ${ }^{2}$, Deborah M. Riby ${ }^{3}$ and Cheryl Graham ${ }^{2}$

${ }^{1}$ Division of Psychology, Northumbria University, Northumberland Building, Newcastle upon Tyne NE1 8ST, UK

${ }^{2}$ Department of Psychology, Glasgow Caledonian University, UK

${ }^{3}$ Department of Psychology, Newcastle University, UK

doi:10.1017/S0007114508971324, Published by Cambridge University Press, 1 April 2008

\section{Reference}

1. Leigh MR, et al. (2008) Lifestyle, glucose regulation and the cognitive effects of glucose load in middle-aged adults. British Journal of Nutrition 100, 1128-1134. doi:10.1017/S0007114508971324. 